\title{
Article \\ Effect of Nano Hydrotalcite on the Aging Resistance of a High Binder Content Stone Mastic Asphalt
}

\author{
João Crucho ${ }^{1, *(1)}$ and José Neves ${ }^{2, *(1)}$ \\ 1 CERIS, Instituto Superior Técnico, Universidade de Lisboa, Avenida Rovisco Pais, 1049-001 Lisbon, Portugal \\ 2 CERIS, Department of Civil Engineering, Architecture and Georesources, Instituto Superior Técnico, \\ Universidade de Lisboa, Avenida Rovisco Pais, 1049-001 Lisbon, Portugal \\ * Correspondence: joao.crucho@tecnico.ulisboa.pt (J.C.); jose.manuel.neves@tecnico.ulisboa.pt (J.N.)
}

check for updates

Citation: Crucho, J.; Neves, J. Effect of Nano Hydrotalcite on the Aging Resistance of a High Binder Content Stone Mastic Asphalt. Appl. Sci. 2021, 11, 9971. https://doi.org/10.3390/ app11219971

Academic Editor: Cesare

Oliviero Rossi

Received: 20 September 2021

Accepted: 21 October 2021

Published: 25 October 2021

Publisher's Note: MDPI stays neutral with regard to jurisdictional claims in published maps and institutional affiliations.

Copyright: (c) 2021 by the authors. Licensee MDPI, Basel, Switzerland. This article is an open access article distributed under the terms and conditions of the Creative Commons Attribution (CC BY) license (https:/ / creativecommons.org/licenses/by/ $4.0 /)$.

\begin{abstract}
Hydrotalcite, a type of layered double hydroxide (LDH), reveals an interesting potential for the modification of bitumen. The LDH can induce a barrier effect that prevents the loss of volatiles, retards oxidation, and protects against ultraviolet radiation. Such properties can enhance the aging resistance of the bitumen. However, there is a gap in knowledge regarding the effects of the modification with hydrotalcite in the properties of the asphalt mixture. To contribute to fill such a gap, the current study presents a characterization of the effects of the modification with nano hydrotalcite in the surface characteristics, mechanical performance, and aging resistance of an asphalt mixture. To better explore the effects of the modification, the selected asphalt mixture was a high binder content (7.5\%) Stone Mastic Asphalt (SMA). The experimental study indicates that the binder-rich SMA presented adequate performance for application in surface courses. If compared to conventional mixtures, the binder-rich SMA presented better initial mechanical performance (unaged conditions). Furthermore, it presented smaller variation in the parameters between unaged and aged conditions, indicating enhanced aging resistance. The modification with nano hydrotalcite induced smaller evolution in the fatigue resistance parameters, indicating enhanced aging resistance; however, in the remaining tests, the trends were not clear.
\end{abstract}

Keywords: stone mastic asphalt; nanomaterials; hydrotalcite; mechanical performance; surface characteristics; aging resistance

\section{Introduction}

Asphalt pavements are a key element of the transport infrastructure, usually, being the dominant structure of the road network. During service life, pavements have to withstand a variety of traffic loads and environmental conditions (e.g., temperature variation, solar radiation, moisture, and oxidation) that will degrade their initial performance. Besides costly, the maintenance of these infrastructures is challenging due to the consequent disruptions in mobility and safety risks. Recent research in pavement engineering is focusing in improving the performance of the materials from economic, environmental and mechanical standpoints.

The surface courses are particularly important because of the direct contact with traffic. The asphalt mixtures applied in surface layer must perform well to provide adequate safety and comfort, coping with exigent requirements for skid resistance and permanent deformation, among others. Moreover, aging is particularly severe in pavement surface courses because they are directly exposed to the environmental conditions. Besides the conventional asphalt concrete (AC), over the years, other types of asphalt mixtures have been developed, for instance, the Stone Mastic Asphalt (SMA) and the Porous Asphalt (PA). In addition, to enhance the performance of these mixtures during the pavement service life, a variety of additives was studied.

In particular, SMA is a gap-graded asphalt mixture that exhibits good performance, especially for application in surface courses due to their high resistance to cracking and 
rutting. The key factor contributing to SMA improved performance is the aggregate interlocking that promotes stone-on-stone contacts in the coarse particles, which does not occur in conventional dense mixes with continuous gradations, and increases resistance to permanent deformation [1-3]. In addition, the high bitumen mastic fulfilling the SMA voids can also enable durability in the long-term pavement life cycle. The improved mechanical and surface characteristics of SMA are responsible for the increased gain of interest in this type of asphalt mixture for application in pavement construction, mainly in heavy-trafficked areas.

The asphalt binder, also designated as bitumen, is a material prone to aging that suffers a deterioration of its properties over the time which affects the performance of respective asphalt mixture [4]. As in many cases conventional bitumen no longer ensures acceptable performance and to address environmental and economic concerns, several modifications (i.e., additives) were developed: temperature reduction (warm mix technology), elasticity (polymers), adhesion improvers, rejuvenators, fibers, and rubber [5-12]. Recently, in attempt to enhance aging resistance, the self-healing technology is being developed. Three self-healing technologies are currently available: nanoparticles, reheating, and rejuvenation $[7,13-17]$.

The use of nanomaterials as additives for asphalt mixtures already demonstrated several benefits regarding mechanical performance and aging resistance [13,18-21]. Generally, the nanomaterials more frequently studied are the nanosilica and nanoclays. Hydrotalcite is considered a layered double hydroxide (LDH) [22,23]. The LDH are ionic lamellar materials composed by positively charged brucite-like layers of organic-inorganic or inorganicinorganic nanomaterials. Compared to conventional clays mineralogical structure, the $\mathrm{LDH}$ possess stronger interactions interlayers thus becoming less prone to delamination. Some research studies have already identified potential applications of LDH in concrete materials [24,25]. Regarding asphalt binders, the use of LDH has also been investigated in last recent years, especially due to the barrier properties. Such property can give protection against ultraviolet radiation, delay oxidation, and retard the loss of volatiles, consequently enhancing the aging resistance of the binder [26-34].

At the binder level, the aging resistance is evaluated through the evolution of rheological parameters after accelerated aging in the laboratory. The mostly used aging methods of bitumen are the thin-film oven test (TFOT), rolling thin-film oven test (RTFOT), and pressure aging vessel (PAV). The dynamic shear rheometer (DSR) and bending beam rheometer (BBR) are the most frequently used types of testing. Several studies concluded that the modification with LDH enhanced its ultraviolet (UV) aging resistance [31,35-37] and flameretardant properties [34,38]. In addition to rheological parameters, Huang et al. [36], using Fourier-transform infrared spectroscopy (FTIR) analysis found that LDH can inhibit the oxidation of bitumen during thin-film oven test (TFOT) and UV aging, resulting in smaller content of carbonyl and sulfoxide groups than in the unmodified bitumen. The modification of bitumen with nano hydrotalcite can enhance the aging resistance of the binder and, accordingly, also of the asphalt mixture. Thereafter, such modification can be more effective in the case of asphalt mixtures with high binder content. Furthermore, to full explore the potential of the modification, namely, the UV aging resistance, it must be considered for asphalt mixtures to be applied in surface courses. Currently, there is a gap in knowledge regarding the effects of the modification with hydrotalcite at the asphalt mixture level.

The objective of this study was to evaluate the effects of modification with nano hydrotalcite on the surface characteristics and mechanical performance of an asphalt mixture to be used in surface courses. For this objective, two asphalt mixtures were produced: (1) a conventional mixture and (2) a mixture modified with nano hydrotalcite. To better potentiate and explore the effects of the modification, the selected asphalt mixture was an SMA produced with a polymer-modified bitumen (PMB 45/80-65). It is expected that the particularly high binder content $(7.5 \%)$ can induce a more significant effect of the modification. An experimental program was developed to characterize the asphalt mixtures, including testing for skid resistance, macrotexture, indirect tensile strength, water 
sensitivity, stiffness, and resistance to fatigue. In addition, to assess possible long-term effects, such as aging resistance, the asphalt mixtures were conditioned for accelerated aging in laboratory, using the long-term oven aging (LTOA) method, and tested afterwards. This paper presents and discusses the results of the experimental program.

\section{Materials and Methods}

\subsection{Materials}

The asphalt mixture selected for the study was a stone mastic asphalt with maximum size of aggregate $8 \mathrm{~mm}$-SMA 8 - designed according to the EN 13108-5 [39]. Figure 1 shows the particle size distribution of the aggregate mixture. Three aggregate fractions, obtained from crushed gabbro rock, were used to achieve the final mixture of aggregates: $0 / 6,2 / 6$, and $6 / 12$ (the numbers $\mathrm{d} / \mathrm{D}$ represent the minimum and maximum nominal sizes of the aggregate fraction). The dosages by mass of aggregates were $7 \%, 19 \%, 54 \%$, and $20 \%$ for the fractions of filler $0 / 6,2 / 6$, and $6 / 12$, respectively.

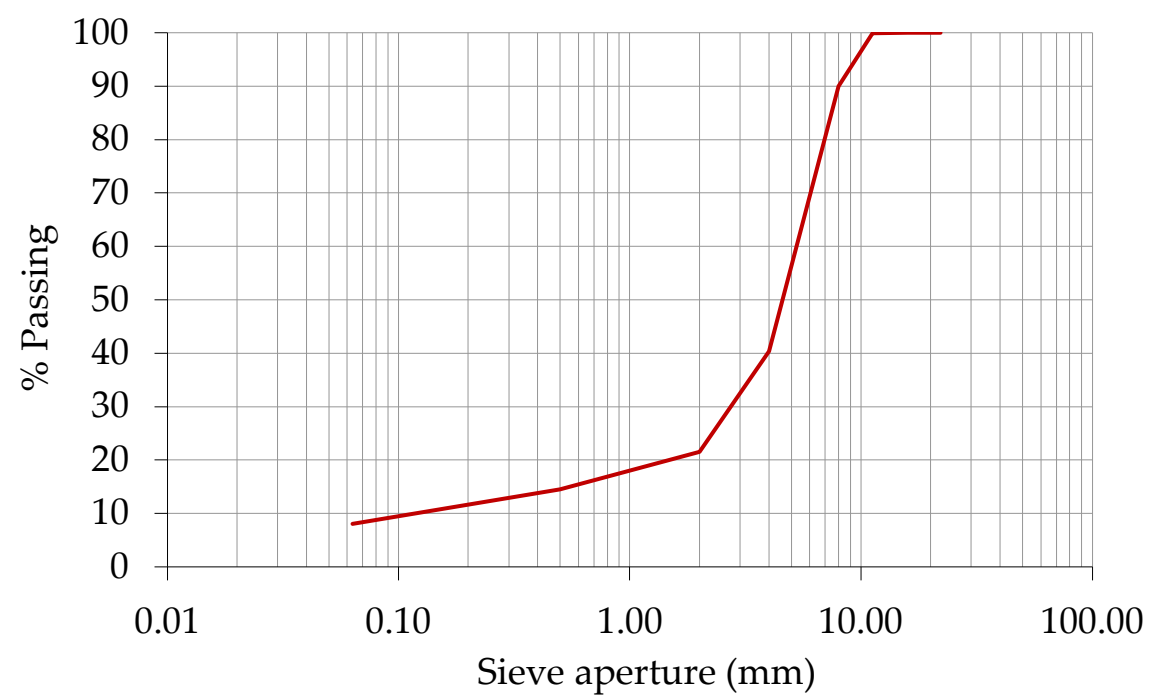

Figure 1. Particle size distribution.

The asphalt mixture can be considered binder rich, as the selected binder content was $7.5 \%$ (by mass of asphalt mixture). The binder was a polymer-modified bitumen, designated as PMB $45 / 80-65$. In addition, $0.5 \%$ of natural cellulose fibers (by mass of asphalt mixture) were added to prevent the occurrence of binder drainage. The main properties of the control asphalt mixture are presented in Table 1.

Two asphalt mixtures were produced: one designated as control (using PMB 45/80-65 binder as supplied), and other designated as modified, where the PMB 45/80-65 binder was modified with $3 \%$ (by mass of final binder) of nano hydrotalcite. The hydrotalcite, also designated as magnesium aluminum hydroxycarbonate, has the following chemical formula: $\mathrm{Mg}_{6} \mathrm{Al}_{2} \mathrm{CO}_{3}(\mathrm{OH})_{16} \cdot 4 \mathrm{H}_{2} \mathrm{O}$. The modification was done by heating the original binder at $160{ }^{\circ} \mathrm{C}$, adding the nano hydrotalcite powder and applying high-speed stirring at $2000 \mathrm{rpm}$ during $60 \mathrm{~min}$. More details regarding the modification process can be found elsewhere [20]. Table 2 presents the physical properties of the control and modified binders. 
Table 1. Properties of the control mixture.

\begin{tabular}{|c|c|c|c|c|}
\hline Property/Type of Test & Test Standard & Parameter & Unit & Value \\
\hline \multirow{5}{*}{ Marshall method } & \multirow{5}{*}{ EN 12697-34 } & Binder content & $\%$ & 7.5 \\
\hline & & Stability & $\mathrm{kN}$ & 6.7 \\
\hline & & Flow & $\mathrm{mm}$ & 3.2 \\
\hline & & Marshall Quotient & $\mathrm{kN} / \mathrm{mm}$ & 2.1 \\
\hline & & Porosity & $\%$ & 4.9 \\
\hline Skid resistance & EN 13036-4 & Pendulum test value (PTV) & n.a. & 58 \\
\hline Surface macrotexture & EN 13036-1 & Mean texture depth (MTD) & $\mathrm{mm}$ & 1.2 \\
\hline \multirow{3}{*}{$\begin{array}{l}\text { Permanent } \\
\text { deformation }\end{array}$} & \multirow{3}{*}{ EN 12697-22 } & Rut depth in air $\left(\mathrm{RD}_{\text {air }}\right)$ & $\mathrm{mm}$ & 3.9 \\
\hline & & Proportional rut depth in air $\left(\mathrm{PRD}_{\text {air }}\right)$ & $\%$ & 7.5 \\
\hline & & Wheel-tracking slope in air $\left(\mathrm{WTS}_{\text {air }}\right)$ & $\mathrm{mm} / 10^{3}$ cycles & 0.286 \\
\hline Indirect tensile strength & EN 12697-23 & Indirect tensile strength (ITS) & $\mathrm{MPa}$ & 2.368 \\
\hline Water sensitivity & EN 12697-12 & Indirect tensile strength ratio (ITSR) & $\%$ & 95 \\
\hline \multirow{2}{*}{$\begin{array}{c}\text { Stiffness } \\
\text { (at } 20^{\circ} \mathrm{C}, 10 \mathrm{~Hz} \text { ) }\end{array}$} & \multirow{2}{*}{ EN 12697-26 } & Stiffness modulus & $\mathrm{MPa}$ & 4565 \\
\hline & & Phase angle & $\circ$ & 22.7 \\
\hline \multirow{2}{*}{$\begin{array}{l}\text { Resistance to fatigue } \\
\quad \text { (at } 20^{\circ} \mathrm{C}, 10 \mathrm{~Hz} \text { ) }\end{array}$} & \multirow{2}{*}{ EN 12697-24 } & $\varepsilon_{5}$ & $\mu \mathrm{m} / \mathrm{m}$ & 403 \\
\hline & & Slope of the fatigue line & n.a. & -5.02 \\
\hline
\end{tabular}

n.a.-not applicable.

Table 2. Properties of control and modified binders.

\begin{tabular}{ccc}
\hline Binder & $\begin{array}{c}\text { Penetration } \\
\times \mathbf{1 0}^{-\mathbf{1}} \mathbf{~} \mathbf{m m}\end{array}$ & $\begin{array}{c}\text { Softening Point } \\
{ }^{\circ} \mathbf{C}\end{array}$ \\
\hline Control & 52.5 & 90.0 \\
Modified & 47.1 & 93.0 \\
\hline
\end{tabular}

\subsection{Methods}

The control and modified SMA 8 were produced and compacted in laboratory. Asphalt mixture production was conducted in a 30-L horizontal axis laboratory mixer, conforming to EN 12697-35 [40]. Cylindrical specimens (approximately with diameter of $101.6 \mathrm{~mm}$ and height of $63.5 \mathrm{~mm}$ ) were compacted using the impact compactor, according to EN 12697-30 [41], applying 50 blows on each side. Prismatic specimens (approximately $400 \mathrm{~mm}$ $\times 300 \mathrm{~mm} \times 50 \mathrm{~mm}$ ) were compacted using the roller compactor, according to EN 1269733 [42]. Prismatic specimens $400 \mathrm{~mm} \times 50 \mathrm{~mm} \times 50 \mathrm{~mm}$ were obtained by sawing the $400 \mathrm{~mm} \times 300 \mathrm{~mm} \times 50 \mathrm{~mm}$ specimens. Regarding test methods, Table 3 lists the parameters evaluated in the laboratory study.

Table 3. Test methods.

\begin{tabular}{|c|c|c|c|c|}
\hline \multirow{2}{*}{ Property } & \multirow{2}{*}{ Test Standard } & \multirow{2}{*}{ Parameters } & \multicolumn{2}{|c|}{ Mixture Conditioning } \\
\hline & & & Unaged & Aged \\
\hline Skid resistance & EN 13036-4 & Pendulum test value (PTV) & $\sqrt{ }$ & $\times$ \\
\hline Surface macrotexture & EN 13036-1 & Mean texture depth (MTD) & $\sqrt{ }$ & $\times$ \\
\hline Indirect tensile strength & EN 12697-23 & Indirect tensile strength (ITS) & $\sqrt{ }$ & $\sqrt{ }$ \\
\hline Water sensitivity & EN 12697-12 & Indirect tensile strength ratio (ITSR) & $\sqrt{ }$ & $\sqrt{ }$ \\
\hline Stiffness & EN 12697-26 & $\begin{array}{l}\text { Stiffness modulus } \\
\text { Phase angle }\end{array}$ & $\sqrt{ }$ & $\sqrt{ }$ \\
\hline Resistance to fatigue & EN 12697-24 & Fatigue lines & $\sqrt{ }$ & $\sqrt{ }$ \\
\hline
\end{tabular}


The surface characteristics of the control and modified asphalt mixtures were evaluated on prismatic specimens $(300 \mathrm{~mm} \times 400 \mathrm{~mm} \times 50 \mathrm{~mm}$ ) compacted using the roller compactor, as this compaction method is more similar to actual field compaction. The skid resistance was evaluated using the pendulum test [43] and the mean texture depth was evaluated using the volumetric patch technique [44].

Regarding mechanical performance, the control and modified SMA 8 were tested for indirect tensile strength, water sensitivity, stiffness and resistance to fatigue. To understand the effects of aging, for both asphalt mixtures—control and modified-a set of specimens was tested under unaged conditions and other set of specimens was tested after accelerated aging. Accelerated aging was conducted in laboratory according to the long-term oven aging (LTOA) method as described in AASHTO R30 [45]. In brief, the LTOA method consists in conditioning the compacted specimens inside a laboratory draft oven at $85{ }^{\circ} \mathrm{C}$ for $120 \mathrm{~h}$. The aged asphalt mixtures were tested for indirect tensile strength, water sensitivity, stiffness, and resistance to fatigue.

The water sensitivity of the asphalt mixtures was determined through the indirect tensile strength ratio (ITSR), by testing the cylindrical specimens for indirect tensile strength (ITS). The ITS tests were conducted according to EN 12697-23 [46] and the water conditioning and ITSR determination according to EN 12697-12 [47]. The test temperature, $15^{\circ} \mathrm{C}$, was selected following the preconized by the Portuguese Infrastructure agency [48].

The stiffness evaluation was conducted according to EN 12697-26-Annex B [49], using the four-point bending (4PB) test. Under controlled temperature, the prismatic specimens $(400 \mathrm{~mm} \times 50 \mathrm{~mm} \times 50 \mathrm{~mm})$ were subjected to a sinusoidal controlled strain loading under the frequencies of $1,3,5,10,20$, and $30 \mathrm{~Hz}$. The selected strain level was $50 \mu \mathrm{m} / \mathrm{m}$. To allow a broader understanding of the stiffness behavior, three test temperatures were selected: $10{ }^{\circ} \mathrm{C}, 20{ }^{\circ} \mathrm{C}$, and $30{ }^{\circ} \mathrm{C}$, respectively.

Resistance to fatigue was evaluated according to EN 12697-24-Annex D [50], using the $4 \mathrm{~PB}$ test. The tests were performed at $20^{\circ} \mathrm{C}$, applying a $10 \mathrm{~Hz}$ sinusoidal loading under controlled strain. The adopted failure criterion was $50 \%$ reduction of the initial stiffness modulus.

\section{Results and Discussion}

\subsection{Surface Characteristics}

The surface characteristics of the control and modified asphalt mixtures were evaluated through the Pendulum Test Value (PTV) and the Mean Texture Depth (MTD). These characteristics are presented in Table 4. For each parameter, the average value and the respective standard deviation (in brackets) are presented. Both asphalt mixtures presented similar results, indicating that the modification with nano hydrotalcite had no particular influence in these properties.

Table 4. Surface characteristics of the control and modified SMA 8.

\begin{tabular}{ccc}
\hline Asphalt Mixture & PTV & $\begin{array}{c}\text { MTD } \\
\text { mm }\end{array}$ \\
\hline Control & $58(4.3)$ & $1.2(0.12)$ \\
Modified & $65(5.2)$ & $1.0(0.09)$ \\
\hline
\end{tabular}

The Portuguese infrastructure agency [48] requires a PTV $\geq 60$, however, indicating that the test can be conducted three months after the pavement is open to traffic. This recommendation aims to ensure that the binder film covering the aggregates was eliminated by traffic. In this study, the pendulum tests were conducted in fresh laboratory compacted specimens, with no binder film removal effect, thus the results obtained for the control and modified mixtures are considered adequate.

Regarding MTD, the Portuguese infrastructure agency [48] does not indicate limit values for SMA, but, for conventional asphalt concrete surface course (for instance, an AC 
10 surf) requires $\mathrm{MTD} \geq 1.0 \mathrm{~mm}$. Considering this criteria, both asphalt mixtures present adequate performance.

\subsection{Mechanical Performance}

\subsubsection{Indirect Tensile Strength and Water Sensitivity}

The asphalt mixtures presented adequate performance in indirect tensile strength (ITS) and indirect tensile strength ratio (ITSR). The results of ITS and ITSR of the control and modified mixtures, under unaged and aged conditions, are presented in Figure 2. The error bars represent the respective standard deviation. ITS $_{\text {dry }}$ and ITS wet $_{\text {are }}$ the ITS of specimens under dry conditions (with no water sensitivity conditioning) and water sensitivity conditioned, respectively.

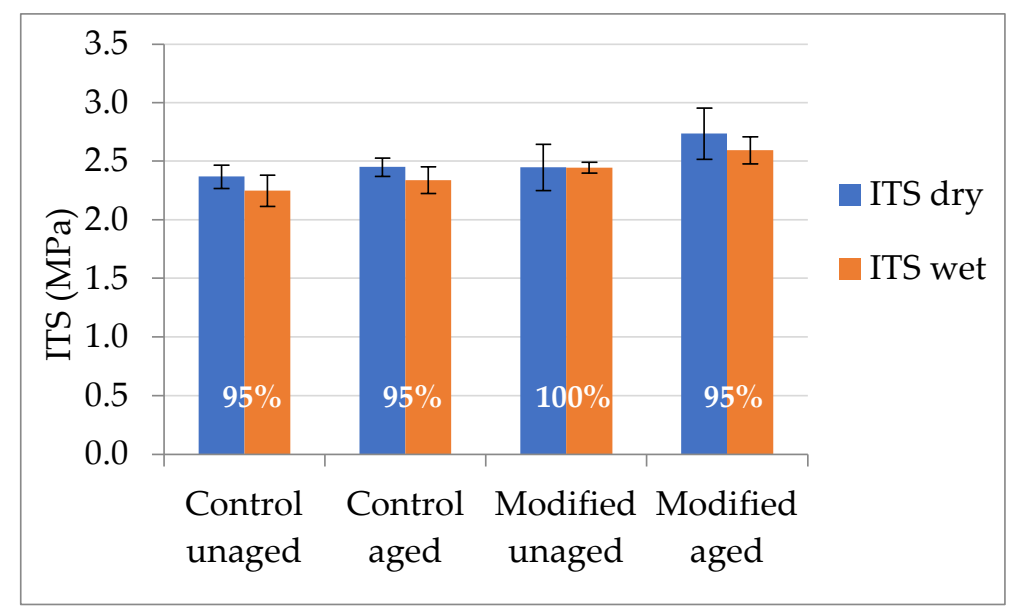

Figure 2. ITS and ITSR of the control and modified SMA 8 in unaged and aged conditions.

However, in general, the differences are within standard deviation, for all aging and conditioning conditions the modified asphalt mixture presented higher ITS. Compared with the control material, the modified asphalt mixture presented $3 \%$ and $12 \%$ higher



As expected, the aging process caused an increase in ITS, that can be explained by the increase of the asphalt mixtures' brittleness. After aging, the control asphalt mixture presented $3 \%$ and $4 \%$ increase in ITS dry $_{\text {and }}$ ITS wet, respectively. In the case of the modified asphalt mixture, after aging the $\mathrm{ITS}_{\mathrm{dry}}$ and ITS wet increased by $12 \%$ and $6 \%$, respectively. The effect of LTOA aging in the ITS of these SMA 8 seems less intensive if compared with conventional asphalt concrete (AC). For instance, in the study of Crucho et al. [51], that used the same test setup, the ITS of a conventional AC 14 mixture (with $4.5 \%$ of bitumen $35 / 50$ ) evolved around $48 \%$, from 1.29 $\mathrm{MPa}$ (unaged) to $1.91 \mathrm{MPa}$ (LTOA aged). Other study [52], that tested (ITS tests at $20^{\circ} \mathrm{C}$ ) a Superpave mixture type SP-III with maximum aggregate size of $19 \mathrm{~mm}$ and $4.4 \%$ of bitumen PG 76-22, identified an increase of $28 \%$ in ITS after LTOA aging (unaged: 1.25 MPa; aged: $1.60 \mathrm{MPa}$ ). The high ITS values, as well as, the smaller effect of LTOA aging in these SMA 8 can be explained by the higher binder dosage and binder type. Regarding water sensitivity, the aging process had no clear effect in ITSR.

\subsubsection{Stiffness}

The results of the stiffness tests, namely, the stiffness modulus and phase angle, are presented in Figures 3 and 4, respectively. Under unaged conditions, in general, regardless of test temperature or loading frequency, the modified asphalt mixture presented lower stiffness modulus than the control asphalt mixture. Regarding phase angle, compared with the control material, the modified asphalt mixture presented higher values for the test temperatures of $20^{\circ} \mathrm{C}$ and $30^{\circ} \mathrm{C}$ and lower values at $10^{\circ} \mathrm{C}$. Under aged conditions, the behavior was similar; however, the differences tended to be smaller. 

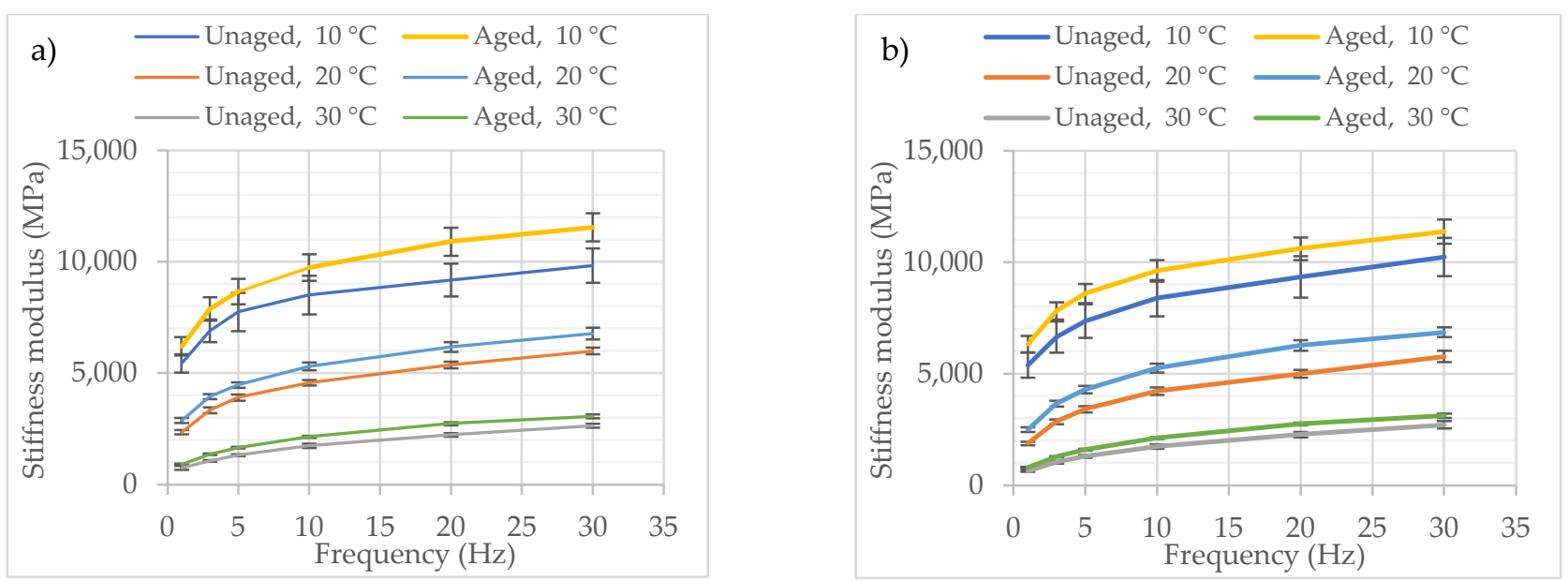

Figure 3. Stiffness modulus of the control (a) and modified (b) SMA 8 in unaged and aged conditions.


Figure 4. Phase angle of the control (a) and modified (b) SMA 8 in unaged and aged conditions.

As expected, the aging process caused an increase of the stiffness modulus and a decrease of the phase angle. For instance, at $10 \mathrm{~Hz}$ and $20^{\circ} \mathrm{C}$, the LTOA aging caused a $16 \%$ and $24 \%$ increase in the stiffness modulus and $2 \%$ and $13 \%$ decrease in the phase angle, for the control and modified asphalt mixtures, respectively. In this regard, the binder-rich SMA was less sensitive to aging than a conventional AC (AC 14 with $4.5 \%$ of bitumen 35/50) tested using the same test setup and equipment [51]. The AC 14 presented $51 \%$ increase in stiffness and $31 \%$ reduction in phase angle (at $10 \mathrm{~Hz}$ and $20^{\circ} \mathrm{C}$ ) after LTOA aging.

\subsubsection{Resistance to Fatigue}

The fatigue lines, and respective coefficients of determination $\left(\mathrm{R}^{2}\right)$, of the control and modified asphalt mixtures under unaged and aged conditions are presented in Figure 5. Complementary results of the fatigue tests, namely, strain corresponding to the application of 100,000 loading cycles $\left(\varepsilon_{5}\right)$ and the slope of the fatigue line (that is an indicator of the mixture's sensitivity to the applied loading strain level), are presented in Figure 6. After the aging process both asphalt mixtures, control and modified, presented worse resistance to fatigue. This behavior was expected, as the aging process causes hardening of the asphalt mixtures inducing a more brittle behavior. Nevertheless, the differences between unaged and aged asphalt mixtures were small, particularly if considering the dispersion of results commonly associated with the fatigue tests. 



Figure 5. Fatigue lines of the control (a) and modified (b) SMA 8 in unaged and aged conditions.


Figure 6. Complementary results of the fatigue tests: $\varepsilon_{5}$ (a) and slope of the fatigue line (b).

Under unaged conditions, compared with the control material, the modified asphalt mixture presented a $16 \%$ reduction in $\varepsilon_{5}$ and $13 \%$ increase in the slope of the fatigue line. However, the aging process caused higher variation in the parameters of the control asphalt mixture. Between unaged and aged conditions, the control asphalt mixture presented variations of $-6 \%$ and $9 \%$ while the modified asphalt mixture presented variations of $-2 \%$ and $-1 \%$, in parameter $\varepsilon_{5}$ and slope of the fatigue line, respectively.

In the case of fatigue resistance, if compared with a conventional $\mathrm{AC}$ the difference between unaged and aged conditions was similar. Between unaged and LTOA aged conditions, an AC 14 with $4.5 \%$ of bitumen 35/50 tested using the same test setup and equipment [51], presented $-4 \%$ of variation in the parameter $\varepsilon_{5}\left(\varepsilon_{5}\right.$ of $244 \mu \mathrm{m} / \mathrm{m}$ and $235 \mu \mathrm{m} / \mathrm{m}$, at unaged and aged conditions, respectively). However, if compared with the conventional AC 14, the fatigue resistance of the binder-rich SMA was superior.

\section{Conclusions}

This study is a contribution to fill a gap in knowledge regarding the effects of the modification with nano hydrotalcite in the properties of an asphalt mixture, particularly, surface characteristics, mechanical performance, and aging resistance. The asphalt mixture under study was a binder-rich Stone Mastic Asphalt with an aggregate upper sieve size of $8 \mathrm{~mm}$. The used binder was a polymer-modified bitumen (PMB 45/80-65) and the binder dosage was $7.5 \%$ by mass. Two asphalt mixtures were studied, one using the supplied binder, and other using the supplied binder modified by adding $3 \%$ of nano hydrotalcite. To evaluate the performance of the asphalt mixtures a laboratory study was conducted, involving testing for skid resistance, mean texture depth, indirect tensile strength, water 
sensitivity, stiffness, and resistance to fatigue. To evaluate the effects of aging, both asphalt mixtures were aged under the LTOA method and subsequently tested for indirect tensile strength, water sensitivity, stiffness, and resistance to fatigue.

The obtained results indicated that the asphalt mixtures presented adequate surface characteristics and mechanical performance for application in surface courses. Regarding surface characteristics, the modified asphalt mixture presented approximately similar behavior to the control materials, having higher skid resistance and lower mean texture depth.

Regarding the initial mechanical performance (unaged conditions), the modified asphalt mixture presented a softer behavior, as indicated by a lower stiffness modulus. The most relevant enhancement of the modification was the increase in the indirect tensile strength and water sensitivity (with an ITSR of 100\%).

The modification with nano hydrotalcite did not present clear contributions regarding a potential enhancement in aging resistance. To assess the effects of aging, the evolution of several mechanical performance parameters, between the unaged and aged conditions, was quantified. However the modified asphalt mixture presented smaller evolution in the fatigue resistance parameters, in the remaining tests the trends were not clear, or actually slightly worse than the control material.

The aged asphalt mixtures presented a more stiff and brittle behavior. As expected, after the aging process, the indirect tensile strength and stiffness modulus increased, and, the phase angle and resistance to fatigue decreased. If compared to conventional surface course asphalt mixtures, the binder-rich SMA tended to present better initial mechanical performance (under unaged conditions). Regarding aging, the binder-rich SMA presented smaller variation in the parameters between unaged and aged conditions, which indicates enhanced durability if compared to conventional asphalt mixtures.

Future studies will evaluate aging mechanisms under more field-like conditions, such as, the combined effects of temperature, solar radiation, and moisture damage.

The paper intended to give a contribution to the research and development of the bituminous mixtures nanomodification. It is a very promising technology regarding more sustainable and long life transportation infrastructures. The results presented in the paper have validated the techniques implemented in laboratory concerning the production and testing of this type of modified bituminous mixtures. However, some important challenges must be faced in near future to promote the generalized development and implementation of this technology in engineering practice. It is the case of supply form and cost of nanomaterials.

Author Contributions: Conceptualization, J.C. and J.N.; methodology, J.C. and J.N.; investigation, J.C. and J.N.; writing — original draft preparation, J.N.; writing—review and editing, J.C. and J.N.; supervision, J.C. and J.N. All authors have read and agreed to the published version of the manuscript.

Funding: This research received no external funding.

Acknowledgments: The authors acknowledge the Laboratory of Transport Infrastructures (LVCT) of the Department of Civil Engineering, Architecture and Georesources, Instituto Superior Técnico, University of Lisbon, and CERIS—Civil Engineering Research and Innovation for Sustainability-for the support of this study.

Conflicts of Interest: The authors declare no conflict of interest.

\section{References}

1. Miranda, H.M.B.; Batista, F.A.; Neves, J.; Antunes, M.D.L. Influence of the aggregate skeleton matrix and volumetric composition on the resistance of stone mastic asphalt to permanent deformation. Road Mater. Pavement Des. 2020, 1-14. [CrossRef]

2. Polaczyk, P.; Ma, Y.; Xiao, R.; Hu, W.; Jiang, X.; Huang, B. Characterization of aggregate interlocking in hot mix asphalt by mechanistic performance tests. Road Mater. Pavement Des. 2021, 22, S498-S513. [CrossRef]

3. White, G.; Almutairi, H. Laboratory and field performance comparison of dense graded and stone mastic asphalt as a runway surface. Int. J. Pavement Eng. 2020, 1-13. [CrossRef]

4. Sirin, O.; Paul, D.K.; Kassem, E. State of the Art Study on Aging of Asphalt Mixtures and Use of Antioxidant Additives. Adv. Civ. Eng. 2018, 2018, 1-18. [CrossRef] 
5. Habbouche, J.; Hajj, E.Y.; Sebaaly, P.E.; Piratheepan, M. A critical review of high polymer-modified asphalt binders and mixtures. Int. J. Pavement Eng. 2018, 21, 686-702. [CrossRef]

6. Behnood, A. A review of the warm mix asphalt (WMA) technologies: Effects on thermo-mechanical and rheological properties. $J$. Clean. Prod. 2020, 259, 120817. [CrossRef]

7. Behnood, A. Application of rejuvenators to improve the rheological and mechanical properties of asphalt binders and mixtures: A review. J. Clean. Prod. 2019, 231, 171-182. [CrossRef]

8. Caputo, P.; Abe, A.A.; Loise, V.; Porto, M.; Calandra, P.; Angelico, R.; Rossi, C.O. The Role of Additives in Warm Mix Asphalt Technology: An Insight into Their Mechanisms of Improving an Emerging Technology. Nanomaterials 2020, 10, 1202. [CrossRef]

9. Gupta, A.; Rodriguez-Hernandez, J.; Castro-Fresno, D. Incorporation of Additives and Fibers in Porous Asphalt Mixtures: A Review. Materials 2019, 12, 3156. [CrossRef] [PubMed]

10. Picado-Santos, L.G.; Capitão, S.D.; Neves, J.M. Crumb rubber asphalt mixtures: A literature review. Constr. Build. Mater. 2020, 247, 118577. [CrossRef]

11. Rossi, C.O.; Teltayev, B.; Angelico, R. Adhesion Promoters in Bituminous Road Materials: A Review. Appl. Sci. 2017, 7, 524. [CrossRef]

12. Slebi-Acevedo, C.J.; Lastra-González, P.; Pascual-Muñoz, P.; Castro-Fresno, D. Mechanical performance of fibers in hot mix asphalt: A review. Constr. Build. Mater. 2019, 200, 756-769. [CrossRef]

13. Crucho, J.; Picado-Santos, L.; Neves, J.; Capitão, S. A Review of Nanomaterials' Effect on Mechanical Performance and Aging of Asphalt Mixtures. Appl. Sci. 2019, 9, 3657. [CrossRef]

14. Tabaković, A.; Schlangen, E. Self-Healing Technology for Asphalt Pavements. In Self-Healing Materials; Hager, M.D., van der Zwaag, S., Schubert, U.S., Eds.; Springer: Berlin/Heidelberg, Germany, 2015; pp. 285-306.

15. Vo, H.V.; Park, D.-W.; Seo, J.-W.; Le, T.H.M. Effects of asphalt types and aging on healing performance of asphalt mixtures using induction heating method. J. Traffic Transp. Eng. (Engl. Ed.) 2019, 7, 227-236. [CrossRef]

16. Pasupunuri, S.K.; Tiwari, D.; Jain, S.; Kumar, P. Self-healing pavements: A revolution in pavement materials. In Proceedings of the IRF World Road Meeting, New Delhi, India, 14-17 November 2017; p. 739.

17. Gulisano, F.; Crucho, J.; Gallego, J.; Picado-Santos, L. Microwave Healing Performance of Asphalt Mixture Containing Electric Arc Furnace (EAF) Slag and Graphene Nanoplatelets (GNPs). Appl. Sci. 2020, 10, 1428. [CrossRef]

18. Martinho, F.C.G.; Farinha, J.P.S. An overview of the use of nanoclay modified bitumen in asphalt mixtures for enhanced flexible pavement performances. Road Mater. Pavement Des. 2017, 20, 671-701. [CrossRef]

19. Yang, J.; Tighe, S. A Review of Advances of Nanotechnology in Asphalt Mixtures. Procedia-Soc. Behav. Sci. 2013, 96, 1269-1276. [CrossRef]

20. Crucho, J.; Neves, J.; Capitão, S.; Picado-Santos, L. Mechanical performance of asphalt concrete modified with nanoparticles: Nanosilica, zero-valent iron and nanoclay. Constr. Build. Mater. 2018, 181, 309-318. [CrossRef]

21. Filippi, S.; Cappello, M.; Merce, M.; Polacco, G. Effect of Nanoadditives on Bitumen Aging Resistance: A Critical Review. J. Nanomater. 2018, 2018, 1-17. [CrossRef]

22. Evans, D.G.; Slade, R.C.T. Structural Aspects of Layered Double Hydroxides. In Layered Double Hydroxides; Duan, X., Evans, D.G., Eds.; Springer: Berlin/Heidelberg, Germany, 2005; pp. 1-87.

23. Wang, Q.; O'Hare, D. Recent Advances in the Synthesis and Application of Layered Double Hydroxide (LDH) Nanosheets. Chem. Rev. 2012, 112, 4124-4155. [CrossRef]

24. Xu, S.; Chen, Z.; Zhang, B.; Yu, J.; Zhang, F.; Evans, D.G. Facile preparation of pure CaAl-layered double hydroxides and their application as a hardening accelerator in concrete. Chem. Eng. J. 2009, 155, 881-885. [CrossRef]

25. Duan, P.; Chen, W.; Ma, J.; Shui, Z. Influence of layered double hydroxides on microstructure and carbonation resistance of sulphoaluminate cement concrete. Constr. Build. Mater. 2013, 48, 601-609. [CrossRef]

26. Cui, P.; Zhou, H.; Li, C.; Wu, S.; Xiao, Y. Characteristics of using layered double hydroxides to reduce the VOCs from bituminous materials. Constr. Build. Mater. 2016, 123, 69-77. [CrossRef]

27. Liu, X.; Wu, S.; Pang, L.; Xiao, Y.; Pan, P. Fatigue Properties of Layered Double Hydroxides Modified Asphalt and Its Mixture. Adv. Mater. Sci. Eng. 2014, 2014, 1-6. [CrossRef]

28. Pang, L.; Liu, K.; Wu, S.; Lei, M.; Chen, Z. Effect of LDHs on the aging resistance of crumb rubber modified asphalt. Constr. Build. Mater. 2014, 67, 239-243. [CrossRef]

29. Peng, C.; Yu, J.; Zhao, Z.; Fu, J.; Zhao, M.; Wang, W.; Dai, J. Preparation and properties of a layered double hydroxide deicing additive for asphalt mixture. Cold Reg. Sci. Technol. 2014, 110, 70-76. [CrossRef]

30. Xu, S.; Li, L.; Yu, J.; Zhang, C.; Zhou, J.; Sun, Y. Investigation of the ultraviolet aging resistance of organic layered double hydroxides modified bitumen. Constr. Build. Mater. 2015, 96, 127-134. [CrossRef]

31. Xu, S.; Yu, J.; Zhang, C.; Yao, T.; Sun, Y. Effect of salicylic acid intercalated layered double hydroxides on ultraviolet aging properties of bitumen. Mater. Struct. 2015, 49, 1235-1244. [CrossRef]

32. Xu, S.; Yu, J.; Hu, C.; Jia, L.; Xue, L. Performance evaluation of asphalt containing layered double hydroxides with different zinc ratio in the host layer. Pet. Sci. Technol. 2017, 35, 127-133. [CrossRef]

33. Zhao, Z.J.; Xu, S.; Wu, W.F.; Yu, J.Y.; Wu, S.P. The Aging Resistance of Asphalt Containing a Compound of LDHs and Antioxidant. Pet. Sci. Technol. 2015, 33, 787-793. [CrossRef] 
34. Zhu, K.; Wang, Y.; Tang, D.; Wang, Q.; Li, H.; Huang, Y.; Huang, Z.; Wu, K. Flame-Retardant Mechanism of Layered Double Hydroxides in Asphalt Binder. Materials 2019, 12, 801. [CrossRef] [PubMed]

35. Wu, H.; Li, L.; Yu, J.; Xu, S.; Xie, D. Effect of layered double hydroxides on ultraviolet aging properties of different bitumens. Constr. Build. Mater. 2016, 111, 565-570. [CrossRef]

36. Huang, Y.; Feng, Z.; Zhang, H.; Yu, J. Effect of Layered Double Hydroxides (LDHs) on Aging Properties of Bitumen. J. Test. Eval. 2012, 40, 734-739. [CrossRef]

37. Bao, S.; Liu, Q.; Norambuena-Contreras, J.; Wang, Z.; Wu, S. Effect of layered double hydroxides addition on the ageing and self-healing properties of asphalt binder. Mater. Res. Express 2019, 6, 075704. [CrossRef]

38. Shen, A.; Wu, H.; Guo, Y.; Yang, X.; He, Z.; Li, Y. Effect of Layered Double Hydroxide on Rheological and Flame-Retardant Properties of Styrene-Butadiene-Styrene-Modified Asphalt. J. Mater. Civ. Eng. 2021, 33, 04020454. [CrossRef]

39. CEN. EN13108-5:2006, Bituminous Mixtures-Material Specifications-Part 5: Stone Mastic Asphalt; European Committee for Standardization: Brussels, Belgium, 2006.

40. CEN. EN12697-35:2004+A1:2007, Bituminous Mixtures-Test Methods for Hot Mix Asphalt-Part 35: Laboratory Mixing; European Committee for Standardization: Brussels, Belgium, 2007.

41. CEN. EN12697-30:2012, Bituminous Mixtures-Test Methods for Hot Mix Asphalt-Part 30: Specimen Prepared by Impact Compactor; European Committee for Standardization: Brussels, Belgium, 2012.

42. CEN. EN12697-33:2003+A1:2007, Bituminous Mixtures-Test Methods for Hot Mix Asphalt-Part 33: Specimen Prepared by Roller Compactor; European Committee for Standardization: Brussels, Belgium, 2007.

43. CEN. EN13036-4:2011, Road and Airfield Surface Characteristics-Test Methods-Part 4: Method for Measurement of Slip/Skid Resistance of a Surface: The Pendulum Test; European Committee for Standardization: Brussels, Belgium, 2011.

44. CEN. EN13036-1:2010, Road and Airfield Surface Characteristics-Test Methods-Part 1: Measurement of Pavement Surface Macrotexture Depth Using a Volumetric Patch Technique; European Committee for Standardization: Brussels, Belgium, 2010.

45. AASHTO. R30-02(2010), Standard Practice for Mixture Conditioning of Hot Mix Asphalt; American Association of State Highway and Transportation Officials: Washington, DC, USA, 2010.

46. CEN. EN12697-23:2003, Bituminous Mixtures-Test Methods for Hot Mix Asphalt-Part 23: Determination of the Indirect Tensile Strength of Bituminous Specimens; European Committee for Standardization: Brussels, Belgium, 2003.

47. CEN. EN12697-12:2008, Bituminous Mixtures-Test Methods for Hot Mix Asphalt-Part 12: Determination of the Water Sensitivity of Bituminous Specimens; European Committee for Standardization: Brussels, Belgium, 2008.

48. IP. Specifications; Portuguese Infrastructure Agency: Almada, Portugal, 2014.

49. CEN. EN12697-26:2012, Bituminous Mixtures-Test Methods for Hot Mix Asphalt-Part 26: Stiffness; European Committee for Standardization: Brussels, Belgium, 2012.

50. CEN. EN12697-24:2012, Bituminous Mixtures-Test Methods for Hot Mix Asphalt-Part 24: Resistance to Fatigue; European Committee for Standardization: Brussels, Belgium, 2012.

51. Crucho, J.; Picado-Santos, L.; Neves, J.; Capitão, S.; Al-Qadi, I.L. Tecnico accelerated ageing (TEAGE)—A new laboratory approach for bituminous mixture ageing simulation. Int. J. Pavement Eng. 2018, 21, 753-765. [CrossRef]

52. Islam, R.; Hossain, M.I.; Tarefder, R.A. A study of asphalt aging using Indirect Tensile Strength test. Constr. Build. Mater. 2015, 95, 218-223. [CrossRef] 